\title{
Sustainability Practice of a Multinational Oil Company in Nigeria: A Case Study
}

\author{
Charles Afam Anosike ${ }^{1}$ \\ ${ }^{1}$ School of Business, Charisma University, Providenciales, Turks and Caicos Islands, British West Indies \\ Correspondence: Charles Afam Anosike, School of Business, Charisma University, Providenciales, Turks and \\ Caicos Islands, British West Indies. E-mail: anosikec@gmail.com
}

Received: December 21, $2016 \quad$ Accepted: January 11, 2017 Online Published: January 25, 2017

doi:10.5539/jms.v7n1p29 URL: http://dx.doi.org/10.5539/jms.v7n1p29

\begin{abstract}
Environmental degradation and socioeconomic dilemma continue to affect agricultural productivity in the Niger Delta of Nigeria. Several works of literature confirm the high level of pollution and contamination of land and water as a result of over 50 years of oil production in the region. The effects of environmental pollution continue to aggravate the hardship of the local people, which generates development friction, threaten oil operation, and mutually contrive relational efforts, by so invoking mistrust between oil companies and the host communities. Sustainability programs of oil companies often provide the channel to engage and promote community relations from which projects are conceived and executed. Despite sustainability efforts of oil companies, the region continues to experience oil spills and environmental degradation.

Hence, the current research explores the sustainability efforts of a multinational oil company to establish whether the company's leadership makes environmental considerations and to identify possible corrections that could be adopted to achieve sustainable value. For this purpose, the paper employed a single case study approach using open-ended interview sessions in collecting data. Research data were gathered from a sample of 20 experienced sustainability practitioners of the oil company, partnering nonprofit organizations, and community leaders through face-to-face semi-structured interviews. Data were segmented and categorized. The data analysis process revealed several themes regarding the challenges and shortfalls of sustainability programs in the region. The evidence found suggests that implementing a transparent and inclusive sustainability management system is essential to enable a systems view in contemplating sustainability programs. In so doing, oil MNCs leaders could enable effective environmental consideration in their sustainability programs to help reinvigorate productive agriculture and ensure continuing oil operation.
\end{abstract}

Keywords: sustainability, oil production, niger delta, environmental stewardship, community relation

\section{Introduction}

Fifty years of independence and increased oil production have rendered farming and fishing industries unproductive in the NDR. The region is an enormous wetland and constitutes nine of the 36 Nigerian states, or $7.5 \%$ of Nigeria, and it is home to 27 million people of which $75 \%$ lives in rural areas (Olufemi, 2010). The area traverses a 560-kilometer coastline which bordered one of the most sensitive wetland regions in the world (Olufemi, 2010). The fact that before oil the Niger Delta environment was pristine does make it plausible that oil production is the proximate cause of the Niger Delta problems. Epstein (2008) contends that sustainability success lies with the ability to understand the causal relationship between actions of the company and its stakeholders. Sustainability refers to an organization's activities that transparently incorporate environment and social concerns in delivering stakeholder value (Quinn \& Dalton, 2009). It is reasonable to suggest that sustainability efforts of oil companies had failed to improve or restore the source of livelihood in the environmentally damaged communities. Effective sustainability efforts, typically, mutually-dependent and demonstrating environmental, social, and economic performance could revive productive agriculture, which is the largest source of their livelihood.

\subsection{Problem Statement}

The people of NDR have experienced over 11 million gallons of oil spills every year over the past five decades (Murphy, 2013). Although oil production provided over $80 \%$ of the total national revenue, the oil companies also caused $62.8 \%$ of the oil spills, which were environmentally destroying the area (Eneh, 2011; Olufemi, 2010). 
The persistent environmental deprivation has reduced the economic value of land and water, affecting over $60 \%$ of the local people, which results in mistrust and negative perception of the oil companies (Adekunle, Igbuku, Oguns, \& Shekwolo, 2013; Imobighe, 2011). Despite sustainability efforts of oil companies, the region continues to experience oil spills and environmental degradation. Improving perceptions of sustainability to consolidate social, environmental, and economic performance is imperative for continuing oil operation and sustained citizen's support. The continuing fragmentation of sustainability perception limits the cognitive framework needed to address sustainability challenges. Accordingly, Epstein (2008) stressed that leaders with inadequate knowledge of sustainability are unlikely to produce the proper strategic framework to drive successful efforts. The particular problem indicated a seeming neglect of environmental restoration by Oil Company's leadership in contemplating sustainability effort.

\subsection{Purpose of the Study}

This study explores sustainability efforts of a multinational oil company in Niger Delta region of Nigeria. The goal of this investigation is to establish whether the oil company's leadership make environmental consideration an integral part of their sustainability practice. Consequently, provide the oil company's leadership with information for improving their sustainability program to help revive productive agriculture and to gain increased support for its continuing operations. It is widely known that the problem of Niger Delta is mainly associated with environmental degradation. And sustainability efforts of oil companies often create the framework to engage the host communities in addressing the negative impact of oil operations and their developmental needs. Application of the findings of this study is expected to receive a wider audience beyond the immediate population of the oil company (case unit) that provided the samples.

\subsection{Theoretical Framework}

In 1956, Jay Forrester created the systems theory and was published in 1958 (Forrester, 1958). An evaluation of the interaction of human minds was conducted in 1971 to find systemic influences in behaviors. In 1991, by combining the different concepts behind systems thinking studies, the dynamics that controlled systemic actions was revealed. Systems thinking is a mindset used to model the behavior of complex systems for a better understanding of the interrelationships within systems. Because sustainability agenda is complex and interconnected, a simultaneous pursuit of environmental stewardship, social security, and financial performance could enable sustainability success. Viewing sustainability holistically should uncover the structural disarrangements and interrelated elements to co-create new possibilities and mutual understanding of the situation. The relational standpoint between elements determines the behavior of the whole (Ackoff, 1971). Systems thinking, as Jay Wright Forrester propounded, provided the concept for oil Multinational Corporations (MNCs) to address sustainability challenges to achieve sustainable development in the Niger Delta region.

\section{Literature Review}

The purpose of the study was to describe the sustainability efforts of a multinational oil company in Nigeria and to identify whether environmental considerations were incorporated. The research questions are as follows: (1) How would you define the term sustainability as used in corporate literature? (2) Describe the ways in which corporate sustainability efforts have enhanced the livelihood of the local people? (3) Describe the ways in which corporate sustainability efforts have addressed the environmental issues in the region? (4) What factors do you think have contributed the most to the Niger Delta Region having the reputation as a "sustainability paradox"? (5) Describe any recommended future changes you would make for improving the expected results of similar projects?

The articles reviewed were relevant to the research problem and provided in-depth knowledge about the way and manner organizations embrace sustainability, the intentions or perceived intentions, the outcome and the need to embrace the triple bottom line: economic, social, and environmental issues for future survival. From the works of literature reviewed two key areas emerged: Rethinking organizational behavior for sustainability and Systems thinking.

\subsection{Rethinking Organizational Behavior for Sustainability}

The culture of sustainability thrives in collaboration, as individuals share experience and adapt to new realities (Ayestaran, 2010). Globalization has uncovered a new interconnectedness of business and the society, which have increased organizational considerations to achieve economic performance (Ayestaran, 2010). Imbibing a culture of sustainability to address the current realities is essential for organizational competitiveness (Frank, 2011). Accordingly, Frank (2011) study, emphasized that conventional way of applying sustainability as a public relation initiative cannot advance the phenomenon. Organizations have continued to make unrealistic decisions for economic reasons. Economic and social dimensions are causal to individual decisions in a firm (Hernandez, 
2012). Seeing sustainability with a multi-dimensional lens, Hernandez (2012) espoused that a broader based achievement is the goal of sustainability, thus understanding stewardship behaviors may empower firms to become sustainable.

Unequivocally, Laszlo \& Zhexembayeva (2011) stipulated that environmental risk such as oil spill can be curtailed by improving operational processes. Cleaning the spill once it occurs is essential as well as paying compensation to maintain reputation and regulation. Laszlo \& Zhexembayeva (2011) insist that creating value involves effective environmental risk mitigation to avoid value destruction. Elaborating on operational processes, Silvius, Schipper, Planko, Van den Brink, \& Kohler (2012) argue that sustainability considerations should include the project, asset, and product life cycle. It is the interrelationship between these cycles that determine operational excellence.

Social change is the essence of achieving sustainability, as Salonen \& Ahlberg (2011) insist that government can play a vital role in enabling increased participation toward social change. A government that promotes good governance encourages voluntary participation in addressing social issues for change success (Salonen \& Ahlberg, 2011). Integrating opportunities deriving from social and environmental stewardship is crucial today for businesses to maximize shareholder value (Karns, 2011; Marcus, 2012). On the other hand, Marcus (2012) described the uncharted waters of sustainability as a daunting task, yet it is undeniably crucial for organizational survival today. Improved environmental actions should enable social performance to reintegrate displaced local people and induce sustainable development.

\subsection{Systems Thinking}

Integrating the expectations of the local people into corporate stewardship strategy should enable sustainable development (Allen, 2012). The partitioning of shareholder value from nature is problematic for sustainability. Emergent properties of nature necessitated a new perspective that reveals the relational underpinnings for achieving sustainability (Allen, 2012). The new perspective is premised on eco-social interconnectedness and builds on human and nature relation to driving sustainable value.

Business and society are a configuration of interconnected systems grounded in dynamic complexity. Coevolving in a limited and restricted natural environment, humans, make decisions that violate the ecosystem capacity (Stevens, 2012). Reinforcing social viewpoint based on systems perspective re-invigorates environmental and social sustainability to harmonize with business (Stevens, 2012; Viswanathan, 2012). Accordingly, systems mechanism normalizes learning to provoke further innovation needed to reduce systemic imperfections. Supporting collective learning, Viswanathan (2012) study, stressed that collective knowledge drives sustainable innovation necessary to achieve sustainable development.

As organizations struggle with the paradox of fitting sustainability into the organizational systems, inadequate knowledge and tools continue to hinder sustainability success. A lack of collective understanding of a complex system reduces the cognitive ability to apply systemic thinking in resolving stakeholder issues (Gallo, 2012). Businesses face societal conflicts, and the unfolding future presents a multi-stakeholder constraint and, if well applied harmonizes shareholder value and societal needs. Emphasizing multi-dimensional approach to addressing sustainability challenges, Gallo (2012) demanded the elimination of linear thinking in decision making, rather embracing systemic thinking would enable greater understanding of organizational stakeholder needs to better manage conflicts. The dilemma facing the commons need appropriate recognition to enable behavioral change for an improved psychology of economic growth (Garrity, 2012). Sustainable development crystallizes through behavioral improvement as social responsibility and ethical governance become normative management. The challenges are hyper-complex; a broader mindset enriches development strides by integrating socioeconomic imbalances into the myopic particularistic mindset (Davidson \& Venning, 2011; Garrity, 2012). Systems thinking provide the broader perspective to help organizations institutionalize sustainability.

The embracing of a multiplicity of views should address the cluster of stakeholders and enable new opportunities deriving from economic, social, and environmental issues. An adequate balance of communication provides a healthy relational system, as relational dysfunction undermines the composition of sustainable value (Kahn, Barton, \& Fellows, 2013). Organizational resilience increases in a balanced relational system as greater cognition of policy actors induce beneficial permanence. A system thinking approach reconciles the relational construct between business and societal needs (Kagan, 2010). Because systems thinking focuses on the interrelatedness of elements within a system, increasing relational interaction may enable an organization's capacity to equalize economic, social, and environmental performance.

Accompanying environmental issues of sustainability is the ill-fated pursuit of materialism that creates social injustice (Fiksel, 2012). Understanding the linkages of sustainability challenges may help organizational 
competitiveness. Utilizing the triple value model, the linkages of value emerges in all three areas of economic, social, and environmental concerns (Fiksel, 2012). Like the industrial revolution, the scale of the sustainability revolution is multidimensional, occurring at multiple levels: cognition, action, and regulation (Burns, 2012). The workplace is an interactive space, and continuous improvement empowers all members as sustainability becomes a collective good (Kira \& van Eijnatten, 2010). The dynamics of collaboration in the workplace provokes emergent complexity that enables distributed competency in the social, environment, and financial domain (Kira \& van Eijnatten, 2010. Continuing reliance on traditional organizational change paradigm undercuts a firm's drive toward sustainability.

\section{Methodology}

A single case study approach was used to investigate sustainability efforts of a multinational oil company operating in the Niger Delta to know whether environmental consideration was made. In so doing, provide information that could improve the cognitive framework of designing, developing and implementing sustainability programs in the region. Using a case study presents a reliable framework for exploring patterns of an event within an organization and its environment. As Yin (2012) noted case studies follow orderly field procedures to elicit information from participants and provide a holistic perspective that represents a critical test of the occurrence.

The technique adopted for the study involved the collection of data through the use of open-ended face-face interviews, which was predicated on the descriptive nature of a qualitative study. In this regard, Fairweather \& Rinne (2012) suggest that a qualitative research uses experiential sampling to clarify meanings and descriptions of the event. In contrast, quantitative research uses numeric descriptions (Upjohn, Attwood, Lerotholi, Pfeiffer, \& Verheyen, 2013). Additional data emerged from interviews with community leaders, and partnering NGO project managers involved in the sustainability projects. Community leaders and NGOs gave accounts of the completed projects and the perceived effects. Through multiple data collection, qualitative methodology presents human perspective and uncovers participants shared belief. The current research conformed to qualitative research procedures in gathering and analyzing data from one organization. Because a qualitative research incorporates exploration and analysis, focusing on one organization enabled greater depth in analyzing the research data.

\subsection{Sampling Methods and Participants}

The 20 participants selected included eight employees (management level) from the subject oil company, three community leaders, and nine partnering NGO project managers. It was assumed that the participants would provide in-depth information through their involvement and mastery of sustainability efforts in the region. On the other hand, it was also expected that participants would not answer questions that would bring disrepute to their organization. The participants selected for the study included experienced individuals with known roles in existing sustainability program in the region. Using a small sample of experienced sustainability practitioners extracted in-depth perceptions of the phenomenon. The sample was the most reliable way to elicit perceptions of experienced individuals. Access to participants was made available by the approving agency of the Nigerian government: National Petroleum Investment Management Services (NAPIMS). NAPIMS granted approval to assist and assigned the public affairs executive of the subject oil firm who selected and organized the participants for the interviews. Information about the purpose of the study was provided to the participants. Participants consented to the purpose of the study and participated voluntarily with no compensation.

\subsection{Data Analysis}

All participants Interview responses were tape-recorded and transcribed for analysis. Data analysis commenced with analyzing the interview transcripts. Analyzing the content of the transcript enabled coding and emerging themes to describe segments of the data. The participants' names were in codes Participant 1 through Participant 20 to ensure confidentiality. The techniques for data analysis included interpretative analysis based on a descriptive framework. A linear explanatory logic reveals meaningful patterns (Yin, 2012). Categorization of data through analytic manipulation provided clarity to the evidence. The analytical strategy provided a thorough examination of the evidence to ensure credible interpretation (Tsang, 2013). Relevant quantitative data emerged that revealed the behavior and perceptions of participants. For this purpose, Yin (2009) put succinctly; certain case study can include quantitative data in an evaluative case to explain the outcome. The NVivo 10 software package facilitated the task of organizing and analyzing data to ensure consistency and validity of the process.

\section{Results}

The results from an analysis of participant responses to the questions revealed three themes: the role of the community, the role of oil companies, and long-term sustainability. The report focused on the general attitudes and 
perceptions of the participants regarding the emergent as mentioned above themes. Figure 1 presents the various nuances that emerged as participants responded to the questions. The numbers from 1-10 indicate the most frequently occurring concepts, from the first most frequent (1) to the tenth most frequent (10). For instance, Community was the first most frequently occurring concept, while the government was the tenth most reoccurring concept.

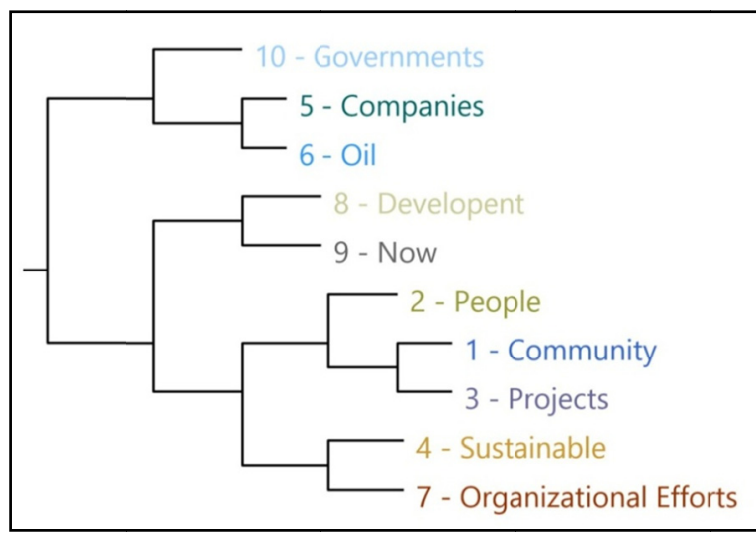

Figure 1. Frequent occurring concepts

The diagram in Figure 1 revealed close ties between the particular concepts that arose in participants' responses. For instance, participants' perceptions regarding organizational efforts were more closely linked to sustainability than they are to government. The following diagram Figure 2, further analyzed the nuances expressed in Figure 1 by using the Pearson correlation coefficient, direct connections between individual concepts were revealed.

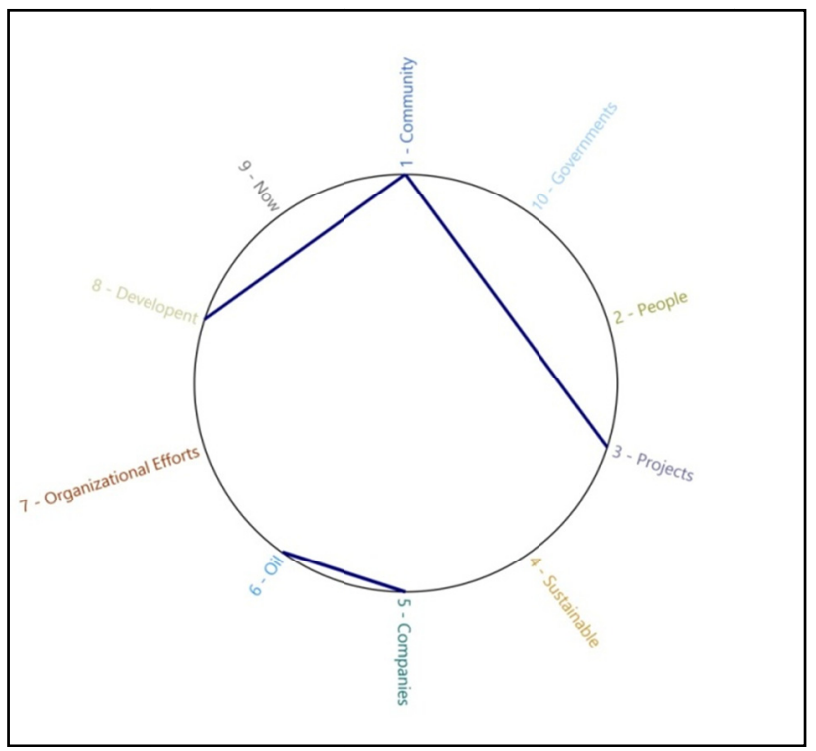

Figure 2. Direct connection between concepts

The above cluster analysis circle graph showed three direct links with the strongest positive relationships: Companies and Oil, Community and Development, and Community and Projects. It can be observed that each of the connections indicated an unyielding positive correlation. The high correlation realized for Companies and Oil explains the dynamic and intimate history between oil companies and Niger Delta region. Explanation of the relationship between Community and Development and Community and Project is contained in the following analysis of participants' responses to each research question.

Participants' responses to question 1: How would you define sustainability as used in corporate literature. Sustainability remains a fragmented notion and for this purpose, obtaining participants different perceptions and 
understanding of sustainability is essential to achieve the research objectives. Participants' perceptions indicated four elements that define corporate sustainability: Corporate Responsibility, Community development, Purposeful projects, and Inclusiveness of people. Among these four elements, inclusiveness of people took precedence. Primarily, participants recognized the role of people as the driving force behind sustainability. This sentiment was summed up well by Participant 11 who stated that sustainability involves planning, involving people in the design, planning, and execution, so that when people own the project, they can put everything they have to sustain it. The second part of the quote further echoed a sentiment about ownership that had been expressed during the interview by some participants. Participant 3, particularly stressed this ownership view, sustainability is not just investing in a support project for communities, but also the ability of the community's stakeholders (the people) to take ownership of those projects and own them, run them and use them to a maximum capacity.

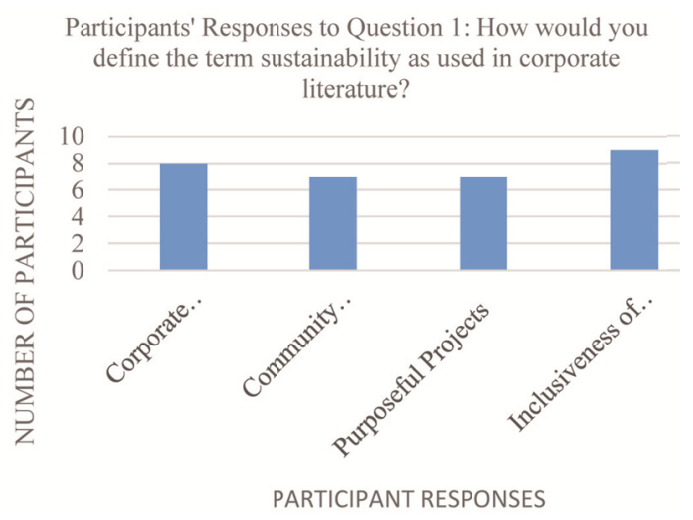

Figure 3. Cluster column. identifying the elements that define corporate sustainability

Figure 4 presents the responses of the participants. According to the figure, $45 \%$ of participants expressed a common understanding of sustainability as the preservation of resources for future generation. Similarly, it was revealed that $25 \%$ of participants (mostly NGO's) perceived sustainability as long lasting non-profit projects/programs of organizations designed solely for the benefit of society. Echoing sustainability as programs designed for societal benefit, Participants 16 stated that the term sustainability means the ability of a project to outlive the sponsors regarding community development. A further 15\% (mostly company executives) defined sustainability separately as company's Corporate Social Responsibility (CSR). Additionally, a minority view of NGO's/Community representatives $(10 \%)$ defined sustainability as public relations activities meant to ensure and maintain the oil companies social license to operate in the host community. Sustainability is a term used in describing the company's ability to do business continuously and not do business in a way that is capable of jeopardizing the company's opportunity of doing business in the future, Participant 13 emphasized.

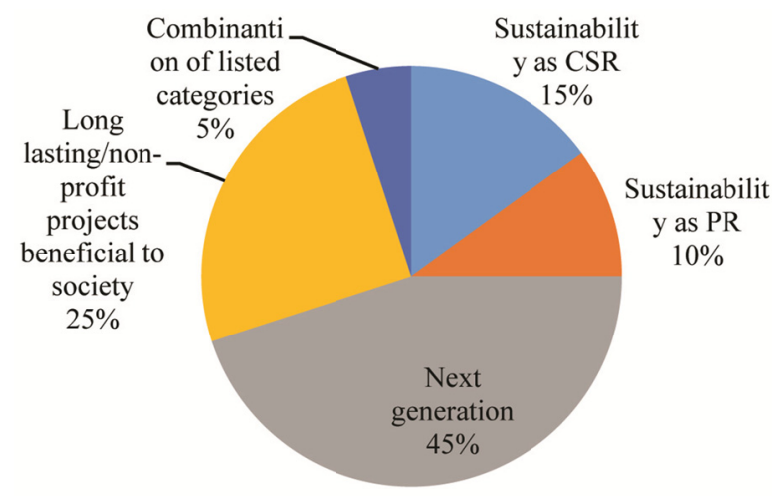

Figure 4. Definition of sustainability 
Participants' responses to Question 2: Describe the ways in which corporate sustainability efforts have enhanced the livelihood of the local people. According to Figure 5, 20\% of participant indicated that Global Memorandum of Understanding-GMOU projects increased the livelihood of local communities by providing infrastructure, capacity building, health facilities, and environmental performance. GMOU is an acronym for Global Memorandum of Understanding. As Participant 13 explained, GMOU is an agreement between the local community, the oil company and the state government. These agreements will typically last 3-4 years and define how a company would relate with and compensate a community (often monetarily) for that period. GMOU model is an agreement that provides greater community involvement in the management of their development activities through the Regional Development Committees-RDC (Bello, 2012). The distribution of participants' responses is as follows: Participants $27 \%$ responded that sustainability efforts provided capacity building. Participant 2 asserted that training of community members is an empowering tool; they learn to conduct a self-directed needs assessment and how to set up small scale enterprise. A further $17 \%$ went for infrastructure, $17 \%$ health facilities, and $13 \%$ were non-specific.

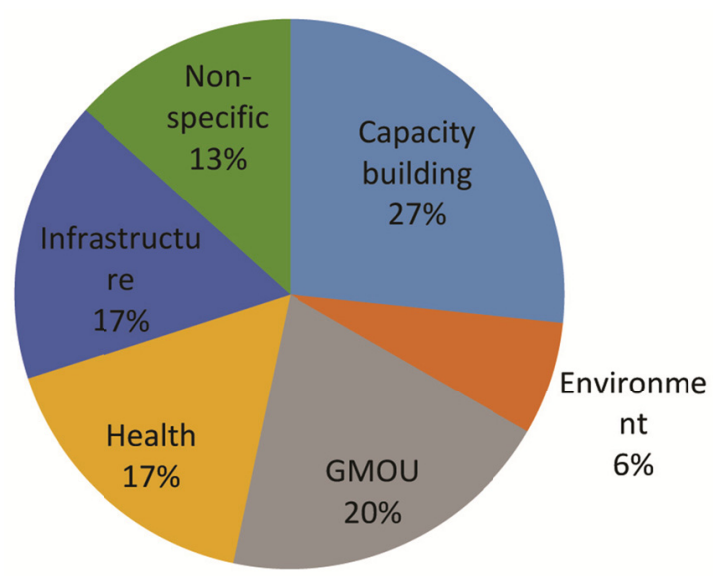

Figure 5. Impact of sustainability efforts on livelihood

Participants' responses to Question 3: Describe the ways in which corporate sustainability efforts have addressed environmental issues. Environmental degradation continues to plague the Niger Delta region as most of their land and water have been rendered unproductive. It can be inferred from participants' responses that sustainability efforts fail to include environmental restoration rather it is used to compensate for the environmental damage by sponsoring developmental projects. Figure 6 presented the distribution of participants' responses. Drawing from Figure 6 participants, 38\% were not able to state specific ways in which corporate sustainability efforts have directly addressed environmental issues in the region, while $9 \%$ said little to none impact. Participants 5\% (one of the NGOs) responded that a mangrove forest had been restored as part of sustainability efforts. Similarly, Participants 5\% (company executive) revealed that some drill sites had been restored and decommissioned.

According to participant 1 (company executive), a number of drill sites have been restored better than what they were before we acquired them several years ago, we have decommissioned the wells and restored the locations back to green vegetation. Participants 19\% (mostly NGO's and community representatives) and $24 \%$ (mostly from company executives) indicated public enlightenment and initiatives as ways in which corporate sustainability efforts have addressed environmental issues in the region. According to Participant 13, the big issue of concern is oil bunkering and theft, the level of vandalization of oil pipelines and the amount of oil spills, as a result, is not something that you want to equal to the occasional oil spill by equipment failure. 


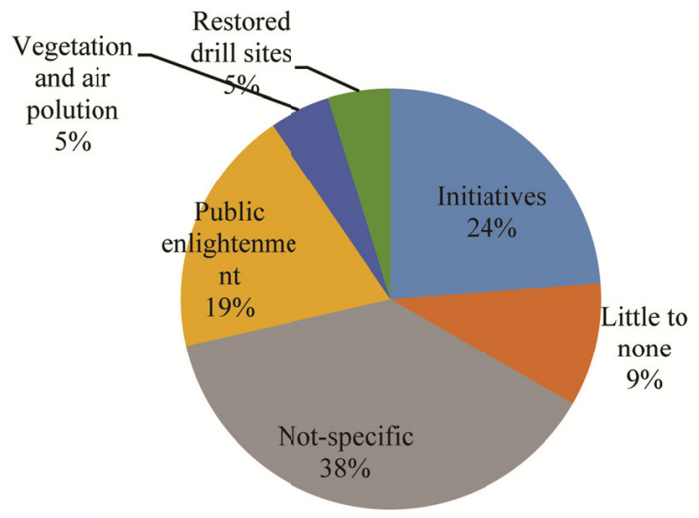

Figure 6. Impact of sustainability efforts on environmental issues

Participants' responses to Question 4: What factors do you think have contributed the most to the Niger Delta region having the reputation as a "sustainability paradox"? Overall, 19 out of 20 participants provided a response to the question from which four factors were identified: Lack of involvement, poor implementation, government failure and neglect, and oil exploitation and theft. Among these four factors, participants' responses favored Government Failure/Neglect as the primary factor behind the Niger Delta sustainability paradox. As Participant 18 put it, the oil companies are doing what government should be doing. This sentiment was shared by the majority of participants, inferring that government has relinquished its responsibility to oil companies and Niger Delta communities.

Responding to the factors that contributed the most to Niger Delta having the reputation as a sustainability paradox, Figure 7 shows the distribution of participants' responses. Participants 42\% (12 out of 20, six executives-6 NGOs/ Community-representatives) blame corruption and failure of governance as the single factor that has contributed negatively regarding sustainability. Similarly, $41 \%$ of participants suggested that multiplicity of problems in the region created the negative sustainability reputation. The problems are multi-faceted, they are not limited to environmental issues; poverty, lack of education, lack of basic road infrastructure, no commitment, it is creeks, where everywhere is water no transportation infrastructure, Participant 2 asserted. Additionally, the absence of infrastructure and remoteness of the region were mentioned, $10 \%$ and $7 \%$ respectively. It can be observed from participants' responses that currently oil comapnies are working to improve community inclusion in project design and management. However, community involvement remains inadequate and falls short of expectation.

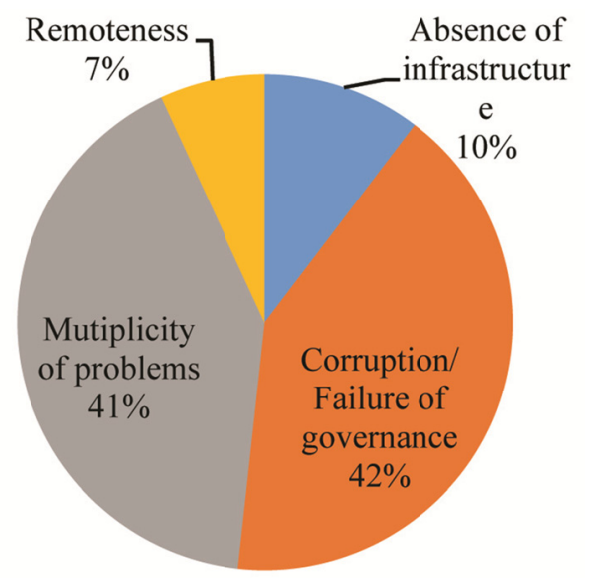

Figure 7. Reputation as a sustainability paradox

Participants' responses to question 5: Describe any recommended future changes you would make for improving the expected results of sustainability projects. Participants' responses provided a recommendation for future changes to improve the expected results of sustainability projects. The need to increase community engagement 
and better planning informed the overriding recommendations from the participants as $36 \%$ ( 8 out of 20 ) emphasized the need to improve community involvement. The majority of participants that expressed this view were from the NGOs/Community representative group. Expressing this view, Participant 1 stated, what I will like to see more is a situation where the communities are involved in certain things they can do very well, like taking care of the forests and helping to identify that rare flora and animals that are almost on the verge of extinction.

An equal number of participants from both company executives and NGOs/Community representatives making up 27\% (6 out of 20) believed that better planning and improved consultation could improve expected results. According to Participant 4, it is essential to provide for adequate consultation to communicate sustainability strategies and incorporate measures that can counter unintended consequences. Other areas that received attention were as follows: Shifting focus to economic empowerment- $14 \%$, getting government more involved-5\%, improving project quality-5\%, monitoring and evaluation-5\%, changing the mindset of local people- $4 \%$, and making sustainability a fundamental part of business- $4 \%$. The general perception from all the 20 participants identified community involvement as the area that needs improvement. Overall, participants' responses demonstrated a convergent understanding regarding increased community inclusion and ownership of projects.

\section{Discussion}

The emerging themes imply that interrelation of elements (social interaction) determined the behavior of the whole (Systems thinking). Supporting the notion of systems thinking, Forrester (1958) insists the relational interaction among elements create new social structures. The different views of sustainability generated increased understanding to enable improved cognitive ability of oil companies' leaders for a rich harmony of business and society. Oil companies' leaders have an obligation to both shareholders and society; as such integrating the actions of diverse actors to formulate a conviction capable of changing the norm, is essential for a new balanced order (Bush, 2013; Forrester, 1958). The productivity of land and water in the Niger Delta could increase when a greater understanding of sustainability induces an integrated framework and consistent stakeholder engagement in oil production. The mechanistic approach of normative management produces a disconnected capitalism not capable of responding simultaneously to economic, social, and environmental pressures. Leaders of sustainable organizations are redirecting their approach, reducing reductionism and embracing co-creation of value toward sustainability.

\section{Conclusion and Recommendation}

The research examines the sustainability efforts of a multinational oil company operating in the Niger Delta region of Nigeria. Based on their perceptions participants were asked a set of 5 questions regarding the sustainability efforts for the essence of determining whether environmental dimension was adopted. The ambiguity and fragmentation of sustainability perceptions in the region remain an obstacle which could have limited the accuracy of participant's responses. It cannot be gainsaid that environmental degradation as a result of oil production has deprived the people of their source of livelihood. Despite the sustainability efforts of oil MNCs leaders, the Niger Delta continues to experience deterioration of environmental and social conditions. From the investigation, it is evident that sustainability practices are used as a tool by oil companies to maintain their social license to operate. It can be observed that global memorandum of understanding-GMOU, which from the findings of the research to date remains the most supported initiative by the host communities.

It is clearly simplistic to view the problem of the region as something that can be curtailed by having an agreed memorandum. Unless oil company leaders start to see beyond this myopic view of sustainability, efforts to gain continuing support for their operations cannot be sustained. Thus, it is important to recognize the interdependence of economic, social, and environmental performance. To acknowledge the pattern of change over time and to understand what is happening in a wholesome way requires a new form of thinking to enable a more proper sustainability mindset. As much as possible, oil companies must develop a new knowledge of systems thinking that will inform a new collaborative sustainability management system.

It can be concluded unequivocally the investigated sustainability practices were ill-contemplated to negate environmental issues, plaguing the Niger Delta. Therefore, oil MNCs leaders must develop a sustainability system instrument panel containing performance indicators of sustainability programs and trends for transparency and accountability. Oil production involves multileveled processes and support systems; therefore, sustainability performance measurement should include an evolving dynamism of economic, social, and environmental (triple bottom line) factors. The sustainability instrument panel should be the basis for assessing performance against the triple bottom line factors as stakeholders monitor and audit the results of the critical 
business processes (Poveda \& Lipsett, 2013). A renewed language of systems thinking can provide the mindset and a diverse set of tools that allow for a deeper understanding of elements of a system and the interrelationships. Most importantly, issues of environmental restoration and productive farming can then be seen as part of an integral sustainability agenda.

\section{References}

Ackoff, R. L. (1971). Towards a system of systems concept. Management Science, 17, 661-671. https://doi.org/10.1287/mnsc.17.11.661

Adekunle, I. M., Igbuku, A. O. O., Oguns, O., \& Shekwolo, P. D. (2013). Emerging trend in natural resource utilization for bioremediation of oil-based drilling waste in Nigeria.

Allen, F. (2012). The enemy within: Oil in the Niger Delta. World Policy Journal, 29(4), 46-53. https://doi.org/10.1177/0740277512470928

Ayestaran, I. (2010). Knowledge, responsibility and ethics of sustainability in view of global change. Ramon Llul Journal of Applied Ethics, 1, 183-198. Retrieved from http://www.rljae.org

Bello, O. (2012). X-raying Chevron's corporate social responsibility. Business Day Online. Retrieved from www.businessdayonline.com

Burns, T. R. (2012).The sustainability revolution: A societal paradigm shift. Sustainability, 4, 1118-1134. https://doi.org/10.3390/su4061118

Bush, A. (2013). Spaces of resonance-towards a complex adaptive systems-based theory of action for sustainability. Proceedings of the International Symposium on Sustainable Systems and Technologies, 2329-9169.

Davidson, K. M., \& Venning, J. (2011). Sustainability decision making frameworks and the application of systems thinking: An urban context. Local Environment, 16, 213-228. https://doi.org/10.1080/13549839.2011.565464

Eneh, O. C. (2011). Crippling poverty amidst corporate social actions: A critique of peripheral corporate community involvement in the Niger Delta Region of Nigeria. Asian Journal of Rural Development, 1, 1-20. https://doi.org/10.3923/ajrd.2011.1.20

Epstein, M. J. (2008). Making Sustainability work: Best practices in managing and measuring corporate social, environmental and economic impacts. San Francisco, CA: Berrett-Koehler.

Fairweather, J., \& Rinne, T. (2012). Clarifying a basis for qualitative generalization using approaches that identify shared culture. Qualitative Research, 12, 473-485. https://doi.org/10.1177/1468794111433000

Fiksel, J. (2012). A systems view of sustainability: The triple value model. Environmental Development, 2, 138-141. https://doi.org/10.1016/j.envdev.2012.03.015

Forrester, J. W. (1958). Industrial dynamics - A major breakthrough for decision makers. Harvard Business Review, 36(4), 37-66.

Frank, G. (2011). How to lastingly fall in love with sustainability. A case for a science of change experiences. Paper presented at the Second International Conference on Sustainability Transitions, Lund, Sweden. Retrieved from http://www.lucsus.lu.se

Gallo, G. (2012). Conflict theory, complexity and systems approach. Systems Research and Behavioral Science, $30,156-175$.

Garrity, E. J. (2012). Tragedy of the commons, business growth and the fundamental sustainability problems. Sustainability, 4, 2443-2471. https://doi.org/10.3390/su4102443

Hernandez, M. (2012). Toward an understanding of the psychology of stewardship. Academy of Management Review, 37, 172-193. https://doi.org/10.5465/amr.2010.0363

Imobighe, M. D. (2011). Paradox of oil wealth in the Niger Delta Region of Nigeria: How sustainable is it for national development. Journal of Sustainable Development, 4, 160-168.

Kahn, W. A., Barton, M. A., \& Fellows, S. (2013). Organizational crises and disturbance of relational systems. Academy of Management Review, 38, 377-396. https://doi.org/10.5465/amr.2011.0363

Karns, G. L. (2011). Stewardship: A new vision for the purpose of business. Corporate Governance, 11, 337-347. https://doi.org/10.1108/14720701111159190 
Kira, M., \& Van Eijnatten, F. M. (2010). Socially sustainable work organizations and systems thinking. Systems Research and Behavioral Science, 27, 713-721. https://doi.org/10.1002/sres.1043

Laszlo, C., \& Zhexembayeva, N. (2011). Embedded sustainability: The next big competitive advantage. Stanford, CA: Greenleaf.

Marcus, J. (2012). Human values and corporate actions propensity: Examining the behavioral roots of societal sustainability. Business and Society, 51, 677-689. https://doi.org/10.1177/0007650312448891

Murphy, M. N. (2013). Petro-Piracy: oil and troubled waters. Orbis, 57, 424-437. https://doi.org/10.1016/j.orbis.2013.05.011

Olufemi, O. (2010). Corporate social responsibility of multinational oil corporations to host communities in the Niger Delta Nigeria. Ife Psychologia, 18(2), 21-35. https://doi.org/10.4314/ifep.v18i2.56641

Omotosho, O. J. (2013). Transnational oil corporations' operations and environmental degradation in Nigeria, 1956-2010. Afro Asian Journal of Social Sciences, 4, 1-22. Retrieved from http://www.onlineresearchjournals.com

Quinn, L., \& Dalton, M. (2009). Leading for sustainability: Implementing the task of leadership. Corporate Governance, 9(1), 21-38. https://doi.org/10.1108/14720700910936038

Salonen, A. O., \& Ahlberg, M. (2011). Towards sustainable society-transforming materialistic consumerism. In H. Lakkala \& J. Vermas (Eds.), Trends and future of sustainable development (pp. 185-201). Helsinki, Finland: Finland Futures Research Centre.

Silvius, G., Schipper, R., Planko, J., Van den Brink, J., \& Kohler, A. (2012). Sustainability in project management. Burlington, VT: Gower.

Stevens, P. (2012). Towards an ecosociology. Sociology, 46, 579-595. https://doi.org/10.1177/0038038511422586

Tsang, E. W. K. (2013). Case study methodology: Causal, contextual, and theorizing. Journal of International Management, 19, 195-202. https://doi.org/10.1016/j.intman.2012.08.004

Upjohn, M. M., Attwood, G. A., Lerotholi, T., Pfeiffer, D. U., \& Verheyen, K. L. P. (2013). Quantitative versus qualitative approaches: A comparison of two research methods applied to identification of two health issues for working horses in Lesotho. Preventive Veterinary Medicine, 108, 313-320. https://doi.org/10.1016/j.prevetmed.2012.11.008

Viswanathan, M. (2012). Curricular innovations on sustainability and subsistence marketplaces: Philosophical, substantive, and methodological orientations. Journal of Management Education, 36, 389-427. https://doi.org/10.1177/1052562911432256

Yin, R. K. (2009). Case study research: Design and methods (4th ed.). Thousand Oaks, CA: Sage.

Yin, R. K. (2012). Applications of case study research (3rd ed.). Thousand Oaks CA: Sage.

\section{Copyrights}

Copyright for this article is retained by the author(s), with first publication rights granted to the journal.

This is an open-access article distributed under the terms and conditions of the Creative Commons Attribution license (http://creativecommons.org/licenses/by/4.0/). 